\title{
Ninho cheio: a permanência do adulto jovem em sua família de origem ${ }^{1}$
}

\author{
Full nest: the young adult remaining \\ at their parent's home
}

\author{
Paula Grazziotin SILVEIRA ${ }^{2}$ \\ Adriana WAGNER ${ }^{3}$
}

\begin{abstract}
Resumo
Este artigo analisa os aspectos psicológicos e psicossociais envolvidos no processo de permanência em casa do adulto jovem solteiro de ambos os sexos. Participaram deste estudo quatro adultos jovens, sendo dois homens e duas mulheres, na faixa etária dos 27 aos 35 anos. Utilizou-se como instrumento da pesquisa uma entrevista semi-estruturada. O método empregado foi o estudo de casos coletivos e fez-se uma análise de conteúdo das informações. Observa-se que a percepção de dificuldade de inserção no mercado de trabalho e da conquista de salários melhores, aliada à vontade de seguir desfrutando do conforto e da segurança que o lar parental oferece, é o grande motivador da permanência dos filhos na casa dos pais.
\end{abstract}

Palavras-chave: adulto jovem; ciclo vital familiar; ninho cheio.

\begin{abstract}
The present article was aimed to analyze the psychological and psychosocial aspects involved in theyoung adult's process of remaining at their parents' home. Fouryoung adults were interviewed, two men and two women, aged from 27 to 35 years old. The method used was Stake's Collective Case Study. Data analysis have been made according to the content analysis method. The difficulty of getting a job and good salaries associated to the wish of continuing enjoying their parents' home comfort and safety is the young adults' main reason to remain at their parents' home.
\end{abstract}

Key words: young adult; family life cycle; full nest.

A clássica idéia que tem perpassado várias gerações de famílias de que "os filhos a gente cria para o mundo" tem sofrido matizes na contemporaneidade. Aspectos relativos à realidade social, política e econômica têm tornado a saída dos filhos da casa paterna cada vez mais difícil. A chamada "fase do ninho vazio", definida na literatura como a etapa evolutiva familiar que culmina com a saída do jovem adulto solteiro de casa, caracterizada pelo processo de independência progressiva do sujeito em relação à sua família de origem, sem romper relações ou fugir reativamente (Carter \& McGoldrick, 1995; Settersten, 1998), tem sido cada vez mais retardada.

\section{$\boldsymbol{\nabla} \mathbf{V} \boldsymbol{\nabla}$}

1 Artigo elaborado a partir da dissertação de P.G. SILVEIRA, intitulada "Ninho cheio: a permanência do adulto jovem em sua família de origem". Programa de Pós-Graduação em Psicologia, Pontifícia Universidade Católica do Rio Grande do Sul, 2004.

2 Professora, Faculdade de Psicologia, Universidade do Planalto Catarinense. Lages, RS, Brasil.

3 Professora Doutora, Faculdade de Psicologia e do Programa de Pós-Graduação, Pontifícia Universidade Católica do Rio Grande do Sul. Av. Ipiranga, 6681, Prédio 11, Sala 931, 90619-900, Porto Alegre, RS, Brasil. Correspondência para/Correspondence to: A. WAGNER. E-mail: <wagner@pucrs.br>. 
Um dado da realidade brasileira é que 81\% das famílias paulistanas nessa etapa ainda possuem pelo menos um filho adulto jovem em casa (Cerveny \& Berthoud, 1997). Na Espanha, 67\% dos rapazes e 49\% das moças de faixa etária entre 25 e 27 anos ainda permanecem vivendo na casa de seus pais (Palacios \& Rodrigo, 1998). Dessa maneira, alguns estudiosos apontam para o surgimento de uma nova fase no ciclo evolutivo da família chamada etapa do "ninho cheio" (Carter \& McGoldrick, 1995; Ríos González, 1994). Ainda pouco estudada, a fase do ninho cheio compreende o processo de permanência dos adultos jovens na residência de sua família de origem.

Certamente, a separação e a individuação iniciam-se desde a mais tenra idade, porém é na juventude, quando a tarefa é "lançar" ao mundo o adulto jovem, que a família e o indivíduo têm que renegociar perdas e ganhos. A experiência de se separar dos pais se constitui um dos fatores essenciais para o alcance da maturidade por parte do adulto jovem. Na cultura ocidental, o ato de sair da casa dos pais significa a porta de entrada para o mundo dos adultos (Henriques, Jablonski \& Feres-Carneiro, 2004).

Esse é um momento crucial do ciclo evolutivo vital familiar. Por parte do jovem, ele experimenta um duplo status de dependência e independência, não sendo completamente autônomo nem totalmente dependente de seus pais (Dey \& Morris, 1999). Por parte da família, os pais sentem-se ambivalentes (Wendling \& Wagner, 2005), com intenção de apoio às iniciativas do filho, entretanto, com sentimento de perda frente à necessidade de redirecionamento de suas funções parentais. Assim sendo, a emancipação gradual é a situação ideal que nem sempre é alcançada pela família (Pittman, 1990).

Nesse sentido, o início e a progressão satisfatória na fase da adultez jovem dependem da resolução das . $\quad$ tarefas do estágio adolescente por parte do filho (Aylmer, 气 1995; Gimeno, 1999). Dessa forma, o processo evolutivo 面 do sistema familiar também é importante, pois se os estágios anteriores do ciclo vital da família ocorreram $\$$ bem, os pais serão mais hábeis em apoiar e se interessar pelas novas tarefas assumidas pelo filho. Em alguns casos, pode acontecer do jovem não conseguir entrar nesse estágio, permanecendo um adolescente em casa, ou pulando esse processo desenvolvimental por meio

442 de um casamento prematuro, por exemplo.
Os pais, assim como podem deixar seus filhos partirem, também podem enredá-los perpetuamente na teia familiar. Nesses casos, a família organiza-se de forma a dificultar a saída de seus filhos de casa em vez de ajudá-los a consolidar seu processo de individuação e construção de uma vida separada e independente. Pesquisa recente com a população brasileira (Wendling \&Wagner, 2005) revela que os pais têm incentivado a permanência de seus filhos em casa por meio do aumento de regalias, cuidados e concessões, como, por exemplo, a permissão para dormir com o namorado no domicílio parental. Nesse sentido, observa-se que atualmente é bastante comum que as famílias lancem mão de estratégias para conviver melhor com as novas necessidades dos filhos adultos que residem no lar parental, considerando que a convivência familiar prolongada tem trazido uma série de vantagens para ambas as gerações (Henriques et al., 2004).

Na cultura brasileira, alguns rituais sinalizam que o adolescente está a caminho de adquirir um status adulto, embora não representem demarcações tão claras disso. A formatura universitária, que antigamente assegurava a entrada do jovem no mercado de trabalho, muitas vezes, delimita o surgimento de uma nova etapa de estudos, no caso de um curso de pós-graduação, não garantindo, necessariamente, sucesso econômico. Atualmente, constata-se um número elevado de jovens que prolongam sua vida estudantil, entrando no mercado de trabalho de maneira mais lenta e gradual (Breunlin, Schwartz \& Kune-Karrer, 2000).

Na Espanha, igualmente, observa-se um maior prolongamento da permanência dos filhos na família, freqüentemente até quase o final da terceira década de vida. Dessa maneira, a família pode ser uma base segura de apoio no caso de necessidades econômicas, enfermidades e problemas laborais (Rodrigo \& Palacios, 1998).

A partir desses pressupostos, o objetivo desse trabalho é conhecer como o adulto jovem percebe e avalia os aspectos psicológicos e psicossociais envolvidos no seu processo de permanência na casa paterna. Sendo assim, investigam-se os motivos que levam o adulto jovem solteiro de ambos os sexos a permanecer na casa de sua família de origem; os aspectos facilitadores e dificultadores da permanência do adulto jovem solteiro em casa e a visão dele a respeito da relação conjugal e parental que se estabelece nessa fase evolutiva vital em sua família. 


\section{Método}

Para respondermos às questões deste estudo, optamos por utilizar a metodologia qualitativa, dentro de uma perspectiva exploratória, a fim de compreendermos o fenômeno e suas peculiaridades. Dessa forma, utilizamos o estudo de caso coletivo descrito por Stake (1994).

\section{Participantes}

O presente estudo contou com a participação de quatro adultos jovens - dois homens e duas mulheres -, na faixa etária entre 27 e 35 anos. Todos os participantes possuíam nível socioeconômico médio e residiam com suas famílias de origem na cidade de Porto Alegre no período da coleta dos dados. Os participantes foram selecionados a partir dos critérios de indicação e conveniência.

\section{Instrumentos}

O instrumento utilizado foi uma entrevista semi-estruturada com um roteiro flexível que abordava os aspectos da estrutura e dinâmica familiar, a avaliação do sujeito sobre o contexto social atual, suas experiências, projetos vitais e motivações. Todos os participantes assinaram um Termo de Consentimento Livre e Esclarecido em duas vias, autorizando a gravação e divulgação dos dados com a preservação do anonimato.

Os dados foram analisados a partir de duas perspectivas: de forma vertical, apoiada na proposta de Análise de Conteúdo de Olabuenága (1999) e de forma horizontal, partindo da entrevista de cada participante e observando as semelhanças e diferenças entre os casos (Stake, 1994).

\section{Resultados e Discussão}

A revisão de literatura e a análise do conteúdo das entrevistas sugeriram três eixos temáticos principais: projetos vitais, aspectos da dinâmica familiar e características do contexto social atual. Sendo assim, a partir de cada um dos eixos temáticos derivaram distintas categorias de análise. Tais eixos e suas categorias nortearam a análise vertical dos casos. Com o objetivo de manter o anonimato dos participantes, os dados biodemográficos e contextuais foram modificados.

\section{Estudo de caso 1 - Pedro}

\section{Dados biodemográficos}

Pedro tem 30 anos, é o último filho de uma prole de três, e o único que ainda reside no lar parental na companhia da mãe. Ele tem duas irmãs mais velhas que já são casadas e têm filhos. No momento da pesquisa, seus pais estavam em processo de reconciliação após terem vivido separados por um período de dois anos. Pedro relatou que seu pai voltaria para casa em breve. A mãe de Pedro tem 63 anos e é professora aposentada. Seu pai tem 65 anos é advogado.

Pedro fez Direito, porém atualmente trabalha como funcionário público num cargo de ensino médio, pois havia feito concurso público para essa função enquanto ainda estava na faculdade. Depois de formado, foi nomeado para tal função. Seu salário no momento da pesquisa era de $R \$ 1.300,00$ por mês (equivalente a 5,4 salários mínimos). O sujeito não tinha namorada, entretanto afirmou ter uma vida social intensa junto a seus amigos.

\section{Projetos vitais}

Ele deixa claro que seu principal projeto vital está centrado no trabalho e, mais especificamente, no desenvolvimento de sua carreira. Ele deseja ascender profissionalmente e, para isso, estuda para concorrer a um cargo público que proporcione um salário melhor e que seja de nível superior na sua área. O desejo de uma melhor remuneração aparece explicitamente vinculado à independência da casa parental: "na primeira oportunidade que tiver, financeiramente falando, gostaria de sair de casa". Nesse sentido, sua maior dificuldade seria "perder o conforto da casa dos pais".

O casamento e a formação de uma família estão entre os projetos vitais de Pedro, porém parece que os projetos laborais têm prioridade em sua vida. Para os 
jovens do sexo masculino, o investimento em uma carreira profissional se apresenta como fundamental. Essa premissa fica explicitada nos estudos de Rocha-Coutinho (2000) que investigou os projetos vitais em adultos jovens brasileiros, revelando que o discurso dos homens tem sido o de que eles se sentem responsáveis pelo bem-estar financeiro da família.

\section{Dinâmica familiar}

A situação familiar de Pedro certamente foi o conteúdo mais enfatizado por ele nessa entrevista. Ele aponta sua família como parte fundamental da situação em que se encontra hoje. Pedro é o único filho que reside no lar da família de origem desde que suas irmãs saíram de casa para casar. A literatura registra evidências de que a saída da residência da família de origem via casamento está culturalmente autorizada, principalmente em se tratando das mulheres (Nilsson \& Strandh, 1999; Settersten, 1998; Vos, 1989).

O sujeito descreve a relação conjugal de seus pais como sendo bastante difícil. Apesar de eles estarem separados há dois anos, Pedro refere que o pai voltará para casa em breve. Os problemas ocorreram, em parte, devido ao alcoolismo do pai. Porém, segundo as informações do sujeito, esse não era o único problema do casal, apesar de sua mãe lhe ter dito quando criança que a culpa pelos conflitos familiares e conjugais era do pai.

Atualmente, o entrevistado consegue ponderar os dois lados ao compreender a relação de seus pais, percebendo a parcela de responsabilidade de ambos na relação. Diz ele: "Os dois nutriam uma relação doentia" em que o pai trabalhava o dia inteiro e, à noite, bebia enquanto a mãe cuidava da família, porém ela não tinha a preocupação com a questão financeira. Ele reconhece que apesar da doença do pai, a mãe também "precisava dessa relação doentia tanto que ele está voltando para casa".

Pedro refere que, durante muito tempo, enxergou seu pai a partir do mesmo ponto de vista de sua mãe, permanecendo, assim, aliado a ela. Com o passar do tempo e com a ajuda da psicoterapia, iniciada havia quatro anos, ele pôde entender a relação conjugal de seus pais de maneira mais crítica, reconhecendo o 444 papel de cada cônjuge e deixando de ver seu pai exclusivamente como"o vilão". Dessa maneira, ele pôde livrar-se do estigma do homem problemático, podendo identificar-se com uma imagem masculina melhor.

Pedro diz que, atualmente, tem por política não se envolver nos assuntos deles, "eles que são adultos que seentendam..." (referindo-se ao relacionamento dos pais). Essa afirmação expressa a tentativa de Pedro manter um distanciamento dos pais a fim de dar-se a possibilidade de seguir em frente sem oferecer-se para ocupar um lugar de intermediador dos membros do casal parental, tentando não se aliar a nenhum deles.

A conflitiva do casal nessa família parece estar contribuindo para que Pedro demore mais a adquirir sua independência emocional e financeira, uma vez que, segundo Pittman (1990), a relação conjugal insatisfatória pode gerar um apego excessivo ao filho por parte dos cônjuges e vice-versa.

Essa idéia se corrobora no desejo que Pedro expressa de que "a mãe tivesse um homem ao seu lado", mesmo que fosse seu pai, já que não Ihe agrada a idéia de ter que deixá-la sozinha em casa. É provável que ele esteja associando a saída de casa com uma situação de abandono da mãe, uma vez que afirma:"se ela tivesse um companheiro, seria mais fácil para eu ir morar sozinho".

\section{Aspectos do contexto social atual}

Pedro aponta o fato de o jovem de hoje querer manter o padrão de vida que a família proporciona. Ele refere que aqueles jovens cuja família oferece mais conforto e favorece uma situação econômica melhor certamente irão optar por seguir vivendo com os pais. "Se tu tiveres a opção de manter o teu padrão de vida o maior tempo que tu puderes até tu poder juntar condições de sair de casa e poder manter esse mesmo padrão, tu vai fazer isso". Desse modo, Pedro refere que muitos dos seus amigos que possuem a mesma idade que ele continuam vivendo e desfrutando do conforto material que o lar parental oferece.

adulto jovem pesquisado refere que é difícil para ele abrir mão do padrão de vida que possui morando em casa. Dessa maneira, a questão financeira é o principal motivo, segundo ele, para continuar residindo com seus pais. 


\section{Compreensão dinâmica do caso}

Observa-se que o motivo explícito para a permanência desse adulto jovem na residência da família de origem é a questão financeira desfavorável. Porém, implicitamente, ele ainda se encontra numa relação de dependência emocional dos pais, o que dificulta o seu desprendimento da família.

Entretanto é importante ressaltar que ele possui uma autocrítica bem desenvolvida, conseguindo perceber o seu papel ativo que contribui para que essa situação permaneça da maneira como está. O primeiro passo talvez já tenha sido dado, na medida em que ele se dá conta daquilo que contribui para que continue em casa. Essa já é uma situação incômoda, uma vez que ele verbaliza claramente sua vontade de partir.

\section{Estudo de Caso 2 - Grace}

\section{Dados biodemográficos}

Grace tem 27 anos e é a filha mais nova, sendo que sua irmã tem 41 anos e também vive na residência parental. Ela formou-se em Enfermagem e atualmente trabalha na área da saúde e faz um curso de especialização em enfermagem domiciliar. Seu salário no momento da entrevista era de $\mathrm{R} \$ 2.500,00$ por mês (equivalente a 9,6 salários mínimos). Grace informou que não estava namorando. Sua mãe tem 61 anos e é dona de casa, o pai tem 60 anos e exerce profissão de nível superior. No ano anterior à pesquisa seus pais adoeceram ao mesmo tempo, necessitando de internação hospitalar. Seu pai teve um problema vascular, e a mãe teve uma severa crise de asma. Diante desse episódio ela passou a considerar ainda mais importante sua família.

\section{Projetos vitais}

Grace demonstrou ser uma jovem muito determinada, expressando claramente aquilo que deseja realizar e, também, aquilo que está fora de seus planos. Seus projetos se baseiam no investimento na carreira para que ela consiga realizar o sonho de ter o próprio negócio. Percebemos que no âmbito profissional ela é bastante exigente consigo própria, tendo trabalhado muito desde a formatura para conseguir aquilo que almeja. Grace mostra o desejo de estar, constantemente, aperfeiçoando-se profissionalmente, o que pode expressar as características do período evolutivo em que ela se encontra, cuja característica é o empenho do sujeito nas conquistas no campo intelectual (Osório, 2001).

Ela afirmou que não tem planos de sair da casa de seus pais, já que não deseja perder o conforto e a segurança que o lar parental Ihe proporciona. Pode-se observar que ela é uma jovem muito apegada afetivamente a seus pais e, provavelmente, esse aspecto pode estar dificultando o seu processo de separação-individuação. Durante a entrevista, Grace comentou que seria difícil ir morar fora da casa de seus pais: "eu ia mesentir sozinha e, certamente, iria querer passar a maior parte do tempo junto deles".

O casamento e a maternidade também fazem parte dos projetos de Grace, como parece ser o caso de muitas jovens que, apesar de mencionarem a profissão como um projeto vital, também referem de maneira quase unânime o desejo de se tornarem mãe (Rocha-Coutinho, 2000).

Entretanto ela diz estar enfrentando dificuldades para encontrar um parceiro para relacionamento sério. Afirma várias vezes, na entrevista, que "os homens atualmente não querem se comprometer". Diante dessa dificuldade ela reage investindo maciçamente na profissão, já que para ela o prioritário é o sucesso profissional. Nessa perspectiva, Jablonski (2005) afirma que os jovens atualmente parecem estar priorizando a realização individual, mantendo perspectivas de vida ligadas à autonomia, à independência e à satisfação pessoal.

\section{Dinâmica familiar}

As informações levam a considerar a possibilidade de que Grace talvez esteja desempenhando o papel de cuidadora de sua família. Além de sua escolha profissional pela enfermagem, ela também escolheu uma especialização em enfermagem domiciliar. A doença e a idade dos pais mobilizam-na muito, uma vez que o temor da morte é proporcional a uma maior dependência em relação a essas figuras (Zilberman, 2002).

Sua família também apresenta características daquilo que chamamos de um "ninho acolhedor" que não proporciona o"lançamento de seus filhos" (Carter \& McGoldrick, 1995). Prova disso é o fato de sua irmã ter 41 
anos e também não explicitar o desejo de sair de casa. Nesse caso, esse sistema familiar apresenta características de funcionamento em prol de que todos permaneçam unidos e coesos, sem fazer desvinculações.

A entrevistada diz que tem feito ameaças de que vai sair de casa quando se desentende com seus pais. Sua mãe, em contrapartida, reage dizendo que elas "não devem brigar por besteiras". A evitação de conflitos parece ser uma estratégia parental que não incentiva a aquisição da independência. No relato de Grace, percebe-se que sua mãe desvaloriza o desejo da filha de adquirir independência em vez de incentivar sua autonomia.

A entrevista revelou que o relacionamento entre ela e sua irmã é muito próximo. Ela refere que sua irmã é alguém com quem ela pode contar quando precisa. Mencionou diversas vezes na entrevista "a gente" quando se referia à irmã. Apesar dessa proximidade, ela diz ser muito diferente da irmã que, em sua opinião, é mais acomodada do que ela.

Quanto às questões econômicas da família, elas aceitam sem oposição a imposição dos pais de que elas têm que contribuir no pagamento dos gastos coletivos da casa. Quando os pais dizem que elas têm que ajudar, elas ajudam sem hesitar, ainda que não haja iniciativa para isso por parte delas de forma espontânea. Observa-se em diversos momentos da entrevista que a família lida com as filhas de maneira infantilizada, o que elas, por sua vez, aceitam passivamente. Essa relação é sentida por Grace como "harmônica". Talvez ela não perceba que esse acolhimento da família esteja desfavorecendo a sua iniciativa já que ela está aceitando as regras de convivência com os pais sem questionamento.

\section{Aspectos do contexto social atual}

No que se refere ao contexto social atual, Grace aponta que nos últimos anos aconteceram diversas minha idade estão acontecendo várias coisas. Há anos atrás acontecia muitas vezes o inverso".

Ela afirma que atualmente a maioria das mulheres procura conquistar sua independência antes de constituir família. "As mulheres se casavam, faziam família e hoje estão voltando a estudar pra conquistar a sua independência. E hoje é bem o oposto, as pessoas estão sozinhas atrás de conquistar o futuro, de se promover 446 profissionalmente".
Ela aponta a dificuldade encontrada por jovens de ambos os sexos para conseguir adquirir autonomia financeira. Refere, ainda, que atualmente as pessoas estão muito mais voltadas para investir na profissão e nos projetos pessoais antes de casar e formar família. Segundo ela, o que acontecia antigamente era o inverso, principalmente no caso das mulheres que, geralmente, casavam e formavam a família, para depois voltarem aos estudos.

\section{Compreensão dinâmica do caso}

Apesar de perceber todas as adversidades da vida cotidiana atual, evidenciadas pela dificuldade de inserção dos jovens no mercado de trabalho, Grace parece estar conseguindo desenvolver-se bem profissionalmente. Ela conquistou um bom emprego e segue estudando para especializar-se cada vez mais em sua área de atuação.

Entretanto, ela parece estar encontrando dificuldades no âmbito pessoal, apresenta-se desacreditada nos relacionamentos com o sexo oposto, tem poucas atividades de lazer, já que dedica bastante tempo ao trabalho.

Ela afirma que é importante tomar uma decisão bem planejada antes de sair e não ir embora da casa dos pais só para dizer que vive sozinha. Talvez essa opinião de aparente responsabilidade esteja indicando que ela está acomodada nessa família e, portanto, não tem o desejo real de sair nesse momento.

Pensa-se que esse sistema familiar esteja incentivando a permanência das duas filhas no lar parental, uma vez que nenhuma delas expressa o desejo real de sair de casa. Nesse caso, provavelmente, a concepção de família esteja fortemente arraigada à idéia de ter e criar filhos. Assim sendo, provavelmente, o distanciamento físico dos membros da família é visto e vivido como ameaçador à integridade do grupo familiar.

\section{Estudo de caso 3 - Carla}

\section{Dados biodemográficos}

Carla é a filha mais velha, com 31 anos; seu irmão tem 27 anos e também vive na residência parental. Ela iniciou duas faculdades: Arquitetura e Administração 
de Empresas, porém não concluiu nenhuma delas. Carla morou no exterior durante quatro anos. Depois disso, realizou um curso de nível técnico em hotelaria. Atualmente, suas atividades principais são estudar inglês e freqüentar a academia de ginástica, já que está desempregada. Carla estava sem namorado no momento da entrevista. Seu pai tem 58 anos e é engenheiro civil. A mãe tem 63 anos, é bióloga e artista plástica.

\section{Projetos vitais}

Carla é uma adulta jovem que ainda não definiu sua identidade profissional. Apesar de ter cursado duas faculdades, ela não conseguiu concluir nenhuma e, por esse motivo, foi viver no exterior. Essa experiência, segundo ela, foi bastante positiva, refere, porém, que não concluiu sua formação devido a essa temporada fora do país e isso está Ihe trazendo dificuldades no momento.

A progressão satisfatória da fase da adultez jovem também depende da resolução das tarefas do estágio adolescente por parte do filho (Carter \& McGoldrick, 1995). Sendo assim, percebe-se que Carla não concluiu uma das tarefas básicas da fase da adolescência que é a definição da identidade pessoal na medida em que ela se define como alguém "meio irresponsável, meio imediatista e meio solteira", ou seja, ela parece não saber precisamente quem ela é.

A identidade profissional, que é um dos aspectos da identidade pessoal, também não está definida por ela, uma vez que ainda não sabe realmente o que gosta de fazer. A irresponsabilidade e o imediatismo são características pessoais auto-referidas que reforçam essa idéia. Entretanto, ela preocupa-se ao ver que os amigos da sua idade já estão direcionados na profissão, exercendo as atividades que escolheram, enquanto ela ainda não encontrou uma ocupação. A entrevistada tinha a sensação de que esses amigos estão envolvidos com as tarefas do mundo adulto, enquanto ela ainda se encontra na fase de transição entre a adolescência e a adultez jovem.

Carla também se mostra incomodada pelo fato do irmão mais jovem afirmar que ela vive confortavelmente como uma adolescente. Nesse caso, pode-se observar que as suas opiniões e percepções para a tomada de decisões baseavam-se, amplamente, em referenciais externos (amigos, pais, familiares). Ela se sente insatisfeita profissionalmente, por exemplo, quando observa seus amigos desempenhando suas profissões. Outra situação que expressa tal funcionamento é a sua decisão de voltar para o Brasil, que se dá em virtude da cobrança dos pais para que ela conclua sua formação universitária. Naquela ocasião, ela retorna, porém, mesmo assim, acaba por não se formar. Observase que sua motivação de voltar tinha muito mais a ver com o desejo de agradar aos pais e atender uma demanda mais deles do que dela de concluir a faculdade.

Nesse sentido, ao longo de seus relatos, pode-se constatar que ela não parece desejar realmente algumas das escolhas que faz. Carla diz que um diploma Ihe faz falta, mas não toma nenhuma atitude para conquistá-lo. Em alguns momentos, suas afirmações soam como imposições que ela mesma se faz, sem revelar desejo por tais projetos. O aspecto econômico aparece bastante elucidado quando afirma: "já vi que vou ter que ter independência financeira." Não aparece como um desejo de "ser independente", mas uma necessidade que parece ser vivenciada por ela como uma imposição.

O principal projeto de Carla é montar um negócio de exportação e importação de equipamentos médicos, e espera, para isso, contar com a ajuda financeira da família. Ela ainda não está convencida de que esse projeto terá sucesso e, então, reage com um comportamento de fuga diante da possibilidade de fracasso, dizendo que se esse plano não der certo sua "válvula de escape" é voltar para o exterior. Sendo assim, demonstra certa imaturidade na dificuldade que expressa em tolerar essa frustração.

\section{Dinâmica familiar}

Carla se mostra bastante dependente da mãe, já que está constantemente perguntando a ela sobre o que fazer nas situações difíceis. Essa"amizade"entre elas - como Carla define a sua relação com a mãe - revela uma confusão de papéis familiares e fronteiras difusas entre os seus membros. Nesse caso, está registrado na literatura que alto grau de proximidade entre os membros da família dificulta a saída dos filhos da casa dos pais (Rosen, Ackerman \& Zosky, 2002). 
Talvez essa família não esteja favorecendo a individuação de seus filhos de maneira adequada, já que parece que os pais não estão conseguindo deixar para trás o controle e o poder característicos de uma relação de superproteção (Cerveny \& Berthoud, 1997). Ainda que eles permitam que a filha vá morar no exterior, solicitam que ela volte para concluir a faculdade e adquirir o diploma aqui no Brasil, denotando a necessidade de controle sobre a vida da filha.

No que se refere à relação conjugal de seus pais, ela diz que eles não são "um casal que deu certo" e que, em sua opinião, eles não se separaram por causa dos filhos. Existe uma crítica velada na fala de Carla com respeito a sua mãe, como sendo uma mulher "fraca", já que não conseguiu se separar de seu pai. Carla tem a idéia de que a mãe poderia estar melhor sem o pai. Nesse sentido, a percepção da fragilidade do vínculo conjugal do par parental pode ser um dos fatores importantes na explicação de sua permanência na casa paterna. O temor do impacto da saída de casa sobre a relação conjugal dos pais é muito freqüente entre os adultos jovens que não percebem uma boa qualidade de relacionamento entre os pais (Pittman, 1990).

Refletindo sobre a aparente insatisfação conjugal dos pais, ela afirma que, no seu caso, isso não acontecerá, uma vez que ela não pretende sustentar um casamento que não dê certo. Em alguns momentos da entrevista, pareceu claramente seu descrédito na durabilidade das relações conjugais ao dizer: "acredito que nenhum relacionamento é capaz de durar para sempre". Pode-se constatar que a percepção e a convivência com um modelo insatisfatório de conjugalidade dos pais se refletem na concepção que Carla tem dos relacionamentos íntimos.

\section{Aspectos do contexto social atual}

Carla comenta que, atualmente, a situação financeira dos adultos jovens está difícil, principalmente para quem está começando numa profissão: "Tu começa a ver a realidade do pessoal que está começando e do pessoal quejá começou: muita gente reclamando". Diante das reclamações de seus amigos, ela sente-se insegura. "E aí tu fica com medo, pensa báh e aí o que é que eu vou fazer, será que eu vou agüentar isso?"

Entretanto ela percebe que muitas pessoas de 448 sua relação já encontraram a profissão e querem exercê- -la, apesar de a situação financeira não ser tão boa. "Tem várias meninas que eu comecei a rever depois de anos. A galera está mais estabilizada. Profissionalmente, nem todo mundo está numa legal, mas é a tua profissão, é o que tu gosta defazer".

Ela acredita que, no aspecto financeiro, a vida no exterior é mais fácil. "Porque infelizmente a economia está ruim, mas aí eu acho que de repente viver lá é muito mais fácil, e tu trabalha muito menos. Com muito menos tempo tu te dimensiona pras coisas. Tu sempre tem grana praviajar, comprar um carro legal. Sempre tem grana pra fazer as tuas coisas".

Na opinião de Carla os jovens de hoje estão demorando mais tempo para sair de casa devido à questão econômica. "Eeu acho que essenegócio de tu viver na casa de pai e mãe é a situação econômica com certeza. Se todo mundo que saísse da universidade já saísse bem empregado. Eu não digo ganhando R\$5.000,00. Mas eu digo um valor que tu mereça por fazer, mas não ser explorado".

\section{Compreensão dinâmica do caso}

Carla demonstra ainda estar oscilando entre momentos de autocrítica, em que reconhece sua parcela de responsabilidade na situação em que se encontra, e uma posição mais acomodada ao pensar que seus problemas podem ser resolvidos com a simples mudança do país.

Em alguns momentos da entrevista ela parecia estar mais consciente das suas dificuldades, porém, em outros momentos, ela voltava a acreditar que a solução está fora do alcance dela. Carla apresentou-se extremamente desanimada com a situação econômica do país e com as dificuldades que os jovens estão enfrentando para conseguir uma colocação no mercado profissional. No entanto, tem pouca consciência a respeito de seus recursos pessoais para alcançar uma situação de maior independência.

\section{Estudo de caso 4 - Felipe}

\section{Dados biodemográficos}

Felipe foi indicado pela participante Carla, que o considerou, para o tema do estudo, um caso inte- 
ressante. Ele tem 35 anos e é formado em Administração de Empresas. Atualmente, trabalha com o pai, que tem 63 anos, no negócio que eles abriram juntos na área de Engenharia Mecânica. Ele é o único filho que mora com os pais, pois sua irmã mais velha foi viver no exterior. Ela está com 38 anos e é casada. Sua mãe tem 63 anos e é dona de casa, já que não deu continuidade aos estudos. Felipe tem uma namorada há seis anos, com quem comprou um apartamento para morarem juntos. Entretanto, devido à falta de estabilidade financeira, decidiram vender o apartamento, pois julgaram não ter condições de manter uma vida a dois.

\section{Projetos vitais}

Felipe afirma que não faz planos para o futuro e essa é a particularidade que mais chama a atenção nesse caso. Ele não expressa o desejo de formar uma família, nem de ser pai, dentre outros desejos que se esperariam em seu momento vital.

Em termos evolutivos, há um ano Felipe deu um passo importante em direção a sua independização quando comprou o apartamento junto com sua namorada. Mas eles decidiram abdicar desse imóvel por não ter condições de manter os gastos de uma vida independente. Pode ser que esse investimento também não tenha sido planejado, já que parece que eles só se deram conta de que não teriam condições de morar juntos depois da compra do imóvel. Conforme relatou Felipe, parece que o jovem casal não antecipou e planejou esse acontecimento. Somado a isso, ele também comentou que nenhum deles possuía renda fixa para dar prosseguimento ao pagamento do imóvel. Esse fato remete à idéia de que o desenvolvimento não é um processo linear, ao contrário, muitas vezes, ele é acompanhado de avanços e retrocessos constantes para, só então, possibilitar que o indivíduo alcance um novo estágio no ciclo evolutivo (Carter \& McGoldrick, 1995). Nesse caso, Felipe realizou um avanço em direção ao seu desenvolvimento, porém, em seguida, recuou tomando a iniciativa de vender o imóvel e permanecer na mesma situação em que estava.

Apesar de o movimento de crescimento não ser um processo sempre progressivo, aparece, nesse caso, um descompasso, refletindo um descompromisso com o futuro. O sujeito entrevistado fala que não se preocupa com o futuro, já que acredita que "vai dar um jeito". Ele considera que à medida que as adversidades forem surgindo, ele as enfrentará, sem que para isso necessite preparar-se antecipadamente. Esse aspecto sugere pensar que ele não se sente como alguém capaz de modificar o meio para conquistar aquilo que almeja (Bronfenbrenner, 1996).

Atualmente, ele trabalha com seu pai, mas talvez esteja exercendo essa atividade muito mais como um "esporte" ou "lazer" do que propriamente como um trabalho. A vestimenta esportiva que ele estava usando no momento da entrevista, que foi no horário e local de trabalho, pode ser considerada um dos indicativos que reforçam essa idéia. A inexistência de uma renda mensal também é outro indicativo, já que ele refere não estar lucrando financeiramente com essa atividade.

\section{Dinâmica familiar}

Felipe demonstrou a necessidade de apoio familiar para exercer suas atividades profissionais. Primeiramente, ele e a irmã montaram uma microempresa para fabricar e comercializar granola e, posteriormente, seu pai idealizou esse negócio em que eles estão envolvidos atualmente. Ele precisou da ajuda e do apoio familiar para concretizar esses dois empreendimentos. Quando sua irmã abandonou o negócio, ele não se sentiu capaz de levá-lo adiante sozinho. Ele demonstra ter raiva e ressentimento da irmã por sua partida, expressando uma sensação de abandono. A evidência disso é que ele conversa com a irmã, esporadicamente, afirmando que foi ela quem se distanciou dele e, portanto, não se sente motivado a procurá-la.

Ele compara bastante a sua relação com a namorada com o relacionamento conjugal de seus pais. Nesse aspecto, aparece a idealização da relação dos pais ao mesmo tempo em que desvaloriza sua relação com a namorada. Nesse sentido, ele afirma que a relação dos pais é mais tranqüila, mais respeitosa e mais livre. Ele e a namorada, por sua vez, enfrentam muitas brigas e discussões.

Sua relação com a mãe parece ser bem próxima. Na sua infância era ela quem cuidava, praticamente, sozinha dos filhos, já que o pai tinha dois empregos. Atualmente, ele refere que ela o aconselha, princi- 
palmente quando o assunto é sentimental. Essa família apresenta um modelo tradicional de estrutura, em que a mãe permanece no mundo privado, responsabilizando-se pelo cuidado dos filhos, enquanto ao pai cabe o sustento econômico do lar e, portanto, a esfera pública (Rocha-Coutinho, 2000).

Felipe, debochadamente, descreve seu pai como um profissional aposentado que continua a trabalhar, pois "ainda tem um filho para sustentar". Felipe realmente acredita que o pai é quem tem que fazer alguma coisa para ganhar mais, já que é dele a responsabilidade pelo sustento da família. Dessa maneira, é o pai quem idealiza o negócio no qual eles estão atuando. Em nenhum momento, Felipe se questiona sobre a possibilidade de seu pai parar de trabalhar e de ele sustentar-se sozinho.

A parentalidade nesse caso ainda é característica de uma família com filhos adolescentes, uma vez que o pai ainda continua desempenhando a função de provedor do filho adulto jovem (Cater \& McGoldrick, 1995).

Felipe, por outro lado, observa que o pai está necessitando cada vez mais de seus cuidados, pois está envelhecendo. Talvez ele se sinta como um filho que tem atribuições de genitor, ou seja, ele se sente responsável pelo cuidado de seus pais, principalmente depois da partida de sua irmã.

\section{Aspectos do contexto social atual}

Felipe reconhece que a questão financeira do país está piorando, principalmente para a classe média. Ele afirma: "A classe média hojeem dia está desaparecendo. Todo mundo que tinha uma situação financeira boa começa a ter que abdicar de uma série de coisas, tem que cortar gasto ali, gasto aqui".

Segundo a opinião de Felipe, as empresas, de modo geral, também têm que cortar custos. "A empresa quer diminuir o custo pra continuar competitiva no mercado. Ela vai pegar sempre o melhor conhecimento possível com o menor custo".

Ele acredita que as empresas preferem pessoas mais jovens e com menos experiência. "Eles preferem sempre uma pessoa que tenha um pouquinho menos de experiência pra poder pagarmenos". Dessa maneira, Felipe percebe que os jovens que estão começando aceitam receber um salário baixo, já que estão aprendendo.
Depois de algum tempo, segundo ele, as pessoas não aceitam mais trabalhar por um salário tão baixo. "Uma pessoa que é mais velha que já viveu um tempo vai dizer olha o meu custo de vida é esse com menos disso eu não posso trabalhar. Já o mais jovem como ainda mora com os pais, está aprendendo..."

\section{Compreensão dinâmica do caso}

Felipe reconhece que o comodismo e a falta de iniciativa são características suas que atrapalham o seu desenvolvimento na medida em que contribuem para que ele continue dependente dos pais. Esse talvez seja o primeiro passo em direção a uma possível mudança.

O pai provavelmente também esteja contribuindo para essa situação se prolongar na medida em que se oferece para continuar ajudando o filho. Talvez ele se sinta culpado e esteja fazendo isso na tentativa de aproximar-se mais de Felipe agora, já que no passado ele esteve bastante ausente em relação aos filhos, pois trabalhava durante o dia e lecionava à noite. Pode-se pensar que ele esteja tentando recuperar o tempo perdido.

Felipe percebe o meio que o cerca como desfavorável para a sua inserção no mercado de trabalho. Sendo assim, apesar de ser relativamente jovem, com 35 anos ele já está se sentindo rechaçado pelo mercado, porque percebe que as empresas tendem a contratar pessoas ainda mais jovens que ele para exercer a mesma atividade.

Certamente, Felipe não está totalmente satisfeito em seguir morando com os pais. Ele sente vontade de ter mais liberdade, mas provavelmente ainda não esteja se sentindo suficientemente incomodado a ponto de tomar uma iniciativa que modifique essa situação.

\section{Análise horizontal e integradora dos casos}

Dando continuidade à discussão dos dados obtidos, desenvolve-se, a seguir, a análise horizontal dos quatro casos estudados, evidenciando as semelhanças e peculiaridades que envolvem o fenômeno.

O primeiro eixo temático, denominado de projetos vitais, aborda os planos que o adulto jovem faz para o seu futuro. Na entrevista, os participantes foram 
questionados sobre como gostariam de estar dentro de um intervalo de cinco e de dez anos. As respostas a essas questões, de maneira geral, contemplaram: projetos pessoais e ocupacionais, investimento na carreira e saída da casa dos pais, tendo aparecido também projetos de formação de uma família por meio do casamento e do nascimento de filhos.

Os entrevistados são unânimes em reconhecer que, atualmente, a inserção no mercado de trabalho está difícil. Aqueles que estão empregados têm como estratégia o investimento na carreira, provavelmente porque acreditam que ainda não alcançaram a condição ideal de trabalho e, principalmente, de salário.

Os outros dois participantes, que estão desempregados, reclamam que está difícil encontrar emprego. No entanto eles não possuem estratégias efetivas para enfrentar tal situação. Ao contrário, parecem tentar contornar as dificuldades do contexto em vez de partir para o real enfrentamento da situação, por mais adversa que se apresente.

Determinados fatores, referidos pelos participantes como facilidades que o lar parental oferece, tornam-se motivos dificultadores da saída de casa devido à dificuldade desse adulto jovem em abrir mão de tais confortos ou regalias. O apoio financeiro dos pais facilita a permanência do filho no lar parental e, nesse caso, dificulta o seu processo de emancipação. Sendo assim, percebe-se que as famílias estudadas, por pertencerem a uma classe mais favorecida economicamente, proporcionam a seus filhos muitas facilidades para que eles continuem morando em casa. Esses filhos acabam tendo dificuldades para deixar de desfrutar do padrão de vida oferecido pelos pais e partir para uma vida independente, com um nível de poder aquisitivo mais baixo, por exemplo.

No segundo eixo temático, aparecem as críticas que o adulto jovem faz a respeito da relação parental e da relação conjugal de seus pais, refletindo a sua percepção sobre a dinâmica familiar. Nesse sentido, é interessante ressaltar que a maior parte dos entrevistados não faz uma boa avaliação do casamento de seus pais.

Possivelmente, essa avaliação negativa que os jovens desse estudo fazem a respeito da relação conjugal dos pais também esteja evidenciando que pais e filhos possuem uma concepção diferente sobre o casamento.
O casamento, apesar de ser desejado, não se constitui como o principal projeto vital dos jovens desse estudo. Talvez o desejo de casar-se esteja sendo evidenciado como uma tarefa evolutiva vital a ser cumprida e não propriamente como um projeto para o futuro como, talvez, tenha sido na geração de seus pais (Zordan, 2002).

A relação parental desses adultos jovens com seus pais parece estar marcada pelo excesso de zelo e cuidado dos filhos em relação aos pais e vice-versa. Esse comportamento evidencia um vínculo frágil nos diversos subsistemas familiares: conjugal, parental e fraterno. A relação de proximidade e dependência aparece também entre os irmãos, como revelam os casos de Grace e de Felipe.

Os casos pesquisados evidenciam que o cumprimento das tarefas evolutivas está sendo arrastado ao longo do ciclo vital. Algumas tarefas da adolescência ainda estão presentes nesses sujeitos, como é o caso da formação da identidade e da busca de autonomia, o que revela que o termo "adultescente"talvez esteja mais apropriado para designar a fase evolutiva em que alguns deles se encontram.

É interessante ressaltar que os jovens desse estudo reconhecem em si mesmos algumas características pessoais como sendo responsáveis pela permanência no lar parental. A falta de iniciativa e o comodismo foram citados por eles como fatores dificultadores do processo de emancipação. As dificuldades na aquisição da autonomia e no desenvolvimento da identidade bem como a vinculação familiar que se estabelece nessas famílias parecem estar favorecendo a dependência do adulto jovem em relação à sua família de origem.

O terceiro eixo temático contempla os aspectos do contexto social que interferem no fenômeno do ninho cheio na visão do adulto jovem. Os participantes desse estudo revelam uma visão crítica a respeito da realidade que os cerca, afirmando pensar bastante a respeito disso.

Na opinião desses adultos jovens, a carreira universitária não garante, necessariamente, o sucesso profissional e financeiro. Alguns deles já estão formados há bastante tempo, porém ainda continuam os estudos e o aperfeiçoamento profissional. Esse prolongamento da vida estudantil está levando a um alargamento do período de pré-lançamento (Carter \& McGoldrick, 1995) 
em que os adultos jovens co-residem com os pais. A expressão "parentalidade longa vida" utilizada por Dey e Moris (1999) parece apropriada para caracterizar os casos estudados, já que os pais em questão continuam oferecendo suporte emocional e financeiro aos filhos por mais tempo.

Essas opiniões evidenciam que os adultos jovens pesquisados fazem uma superexigência do contexto, depositando altas expectativas no meio em que estão inseridos. Essa expectativa de salários elevados e melhores condições acabam sendo frustradas, o que conduz à desesperança. De modo geral, eles não se sentem capazes de fazer algo para mudar a situação. Sendo assim, acabam por não investir no contexto e pensam que não há muito o que fazer. Certamente essa é uma atitude fatalista que os jovens dessa pesquisa apresentam. A percepção de dificuldade de inserção no mercado de trabalho e de conquista de salários melhores, aliada à vontade de seguir desfrutando do conforto e da segurança que o lar parental oferece, aparece como o grande motivador explícito da permanência dos filhos na casa dos pais.

\section{Considerações Finais}

O fenômeno do "ninho cheio", que ocorre quando o adulto jovem segue residindo com sua família de origem, sem emancipar-se financeira e emocionalmente de seus pais, merece atenção pela tamanha freqüência com que vem ocorrendo em nossa sociedade. Pode-se pensar que essa é uma nova forma de organização familiar que vem surgindo, também, em resposta às difíceis condições sociais do momento.

No nível macrossistêmico, a sociedade espera que as famílias se ajustem a um ciclo normativo, mais ou menos flexível, dependendo da cultura vigente. As famílias, por sua vez, sentem-se pressionadas a cumprir essas expectativas sociais. Provavelmente, esse seja um momento de transição em que observamos, em larga escala, o fenômeno do ninho cheio, em que, tradicionalmente, seria esperado o contrário, ou seja, a saída dos filhos da casa dos pais, que caracteriza o ninho vazio.

É necessário enfatizar que esse estudo reflete um fenômeno contextualizado no momento específico em que foi realizado, já que aborda um tema da atualidade numa sociedade em constante transformação.
Cabe ressaltar que essa pesquisa se deteve, exclusivamente, na visão do adulto jovem de nível socioeconômico médio sobre a sua permanência na família de origem, a fim de poder aprofundar o fenômeno a partir dessa perspectiva. Seria importante, em estudos futuros, a abordagem dessa temática a partir da perspectiva dos pais sobre o fenômeno. O trabalho com o subsistema parental faz-se necessário, principalmente por meio do enfoque sobre a conjugalidade que, às vezes, necessita ser reavaliada nessa fase.

Certamente, é preciso integrar os âmbitos psicológico e social para a compreensão desse fenômeno. Entretanto os participantes dessa pesquisa revelaram que algumas questões psicológicas, como é o caso da formação da identidade e da aquisição de autonomia, interferem na forma como esse adulto jovem apreende o meio que o cerca e desenvolve estratégias para conquistar seus projetos. Dessa maneira, pode-se observar que as variáveis familiares e individuais foram preponderantes para a explicação do fenômeno nos casos estudados.

Dentre as fases do ciclo vital familiar normalmente encontramos a etapa denominada de ninho vazio para caracterizar e descrever o funcionamento das famílias em que os pais estão com idade, aproximadamente, entre os 40 e 60 anos, fazendo parte da chamada população de meia idade, e os filhos, que estão com condições de sair do ambiente familiar para iniciar uma vida independente.

Por isso, a variação da etapa do ninho vazio, denominada nesse estudo de fenômeno do ninho cheio, necessita ser estudada e acrescida às tradicionais fases do ciclo vital familiar. A principal tarefa familiar nessa etapa é a emancipação física e emocional do adulto jovem em relação à família.

Os pais devem ter a capacidade de tolerar a ambigüidade na identidade profissional dos filhos adultos e aceitar a variação das ligações emocionais e dos estilos de vida fora da família. O filho, por sua vez, deve resolver as tarefas do estágio adolescente.

Para tanto, é fundamental o empenho no cumprimento das tarefas que cada um dos subsistemas deve desempenhar para que o desenvolvimento dos membros da família ocorra sem o acúmulo das mesmas para as fases subseqüentes.

Cabe, então, aos profissionais que, direta ou indiretamente, lidam com esse fenômeno em sua ativi- 
dade laboral, considerar essa nova forma de organização familiar que vem surgindo, naturalmente, de maneira que possibilite a família compreender adequadamente os acontecimentos inerentes a essa fase, considerando as condições sociais e econômicas atuais. Qual é o tempo certo, a hora " $\mathrm{H}$ " de esvaziar o ninho? Qual a necessidade de cada um? Quem sabe?

Lembrando Gibran Kalil Gibran: "Vossos filhos não são vossos filhos, são os filhos e as filhas da ânsia da vida porsimesma....

\section{Referências}

Aylmer, R. C. (1995). O lançamento do adulto jovem solteiro. In B. Carter \& M. McGoldrick. As mudanças no ciclo de vida familiar: uma estrutura para a terapia familiar (2a. ed.). Porto Alegre: Artes Médicas.

Breunlin, D. C., Schwartz, R. C., \& Kune-Karrer, B. M. (2000). Metaconceitos: transcendendo os modelos de terapia familiar (2a. ed.). Porto Alegre: Artes Médicas.

Bronfenbrenner, U. (1996). Developmental ecology through space and time: A future perspective. In P. Moen. (Org.) Examinig lives in context. Washington, DC: American Psychological Association.

Carter, B., \& McGoldrick, M. (1995). As mudanças no ciclo de vida familiar: uma estrutura para a terapia familiar (2a. ed.). Porto Alegre: Artes Médicas.

Cerveny, C. M. O., \& Berthoud, C. M. E. (1997). Família e ciclo vital: nossa realidade em pesquisa. São Paulo: Casa do Psicólogo

Dey, I., \& Morris, S. (1999). Parental support for young adults in Europe. Children and Youth Servicer Review, 21 (11/12), 915-935.

Gimeno, A. (1999). La familia: el desafío de la diversidad. Barcelona: Ariel.

Henriques, C. R., Jablonski, B., \& Feres-Carneiro, T. (2004). A "Geração Cangurú": algumas questões sobre o prolongamento da convivência familiar. Psico, 35 (2), 195-205.

Jablonski, B. (2005). Atitudes de jovens solteiros frente à família e ao casamento: novas tendências? In T. Féres-Carneiro (Org.), A Família e o casal: efeitos da contemporaneidade. Rio de Janeiro: Editora PUC-Rio.

Nilsson, K., \& Strandh, M. (1999). Nest leaving in Sweden: The importance of early educational and labor market carriers. Journal of Marriage and the Family, 61 (4), 1068-1079.
Olabuénaga, J. I. R. (1999). Metodología de la investigación cualitativa. (2a. ed.). Bilbao: Universidad de Deusto.

Osório, C. M. S. (2001). Adultos jovens, seus scripts e cenários. In C. L. Eizirik, F. Kapczinski \& A. M. S. Bassols (Orgs.), O ciclo da vida humana:uma perspectiva psicodinâmica. Porto Alegre: Artmed.

Pittman, F. (1990). Momentos decisivos: Tratamiento de familias en situaciones de crisis. Buenos Aires: Paidos.

Ríos González, J. A. (1994). Manual de orientación y terapia familiar. Madrid: Fundación Instituto de Ciencias del Hombre.

Rocha-Coutinho, M. L. (2000). Do conto de fadas aos super-heróis: Mulheres e homens brasileiros reconfiguram identidades. Psicologia Clínica, 12 (12), 65-82.

Rodrigo, M. J., \& Palácios, J. (1998). Familiay desarrollo humano. Madrid: Alianza.

Rosen, E., Ackerman, L., \& Zosky, D. (2002). The sibling empty nest syndrome: The experience of sadness as siblings leave the family home. Journal of Human Behavior in the Social Environment, 6 (1), 65-80.

Settersten, R. A. (1998). A time to leave home and a time never to return? Age constraints in the living arrangementes of Young adults. Social Forces, 76 (4), 1373-1400.

Stake R. (1994). Case studies. In Denzin, N. Handbook of qualitative research. Thousand Oaks: Sage Publications.

Vos, S. (1989). Leaving the parental home: Patterns in six latin American countries. Journal of Marriage and the Family, $51,615-626$.

Wendling, M. I., \& Wagner, A. (2005). Saindo da casa dos pais: a construção de uma nova identidade familiar. In A. Wagner (Coord.), Como se perpetua a família? A transmissão dos modelos familiares. Porto Alegre: EDIPUCRS.

Zilberman, A. B. (2002). A concepção de morte em adultos jovens no processo de individuação. Dissertação de mestrado não-publicada, Faculdade de Psicologia, Pontifícia Universidade Católica do Rio Grande do Sul, Porto Alegre.

Zordan, E. P. (2002). O casamento na contemporaneidade: motivos, expectativas, atitudes e mitos. Dissertação de mestrado não-publicada, Faculdade de Psicologia, Pontifícia Universidade Católica do Rio Grande do Sul, Porto Alegre.

Recebido em: 12/1/2005

Versão final reapresentada em: 17/5/2006

Aprovado em: 30/6/2006 
